\title{
Medios de comunicación, redes sociales y virus del miedo, durante la pandemia de COVID-19
}

\author{
Media, social networks and the fear virus during the COVID-19 pandemic
}

\author{
Dra. Pastora Moreno-Espinosa \\ Universidad de Sevilla | Calle Américo Vespucio, s/n, 41092 Sevilla | España | \\ https://orcid.org/0000-0001-6494-130X | pamoreno@us.es
}

\author{
Dr. Javier H. Contreras Orozco \\ Universidad Autónoma de Chihuhua | C. Escorza 900, Col. Centro 31000 Chihuahua| México | \\ jcontreraso@uach.mx
}

\author{
Dra. Aránzazu Román-San-Miguel \\ Universidad de Sevilla | Calle Américo Vespucio, s/n, 41092 Sevilla | España | \\ https://orcid.org/0000-0002-9131-2629| arantxa@us.es
}

Fechas | Recepción: 27/04/2021| Aceptación: 30/05/2021

\begin{abstract}
Resumen
Los medios de comunicación, como altavoces de la sociedad, pueden ser quienes ayuden en las situaciones de crisis a calmar a la población o a generar un clima de prudencia que puede desembocar en miedo hacia lo desconocido. En este artículo se reflexiona, a través del análisis del discurso, sobre el pensamiento único al que Marcuse (1984) denominó "el hombre unidimensional" y cómo éste sigue imperando en la sociedad actual, apreciándose de forma explícita durante la pandemia generada por la enfermedad COVID-19 provocada por un tipo, que hasta el momento era desconocido, de coronavirus. Además, se hace un paralelismo de la difusión de la pandemia en España y en México.
\end{abstract}

En España el virus se ha convertido en el principal problema que es necesario erradicar mientras que en México, este virus ha venido a tapar un problema aún mayor en el país, el caso de la espiral permanente de violencia que vive. A través del análisis de las informaciones

\begin{abstract}
The media, as the loudspeakers of society, can be the ones who help in crisis situations to calm the population or to generate a climate of caution that can lead to fear of the unknown. This article reflects, through discourse analysis, on the single thought that Marcuse (1984) called "the one-dimensional man" and how it continues to prevail in today's society, explicitly appreciated during the pandemic generated by the COVID-19 disease caused by a hitherto unknown type of coronavirus. In addition, a parallel is drawn between the spread of the pandemic in Spain and in Mexico.
\end{abstract}

In Spain, the virus has become the main problem that needs to be eradicated, while in Mexico, this virus has come to cover up an even greater problem in the country, the case of the permanent spiral of violence it is experiencing. Through the analysis of the information that appeared in different Spanish media about the pandemic in Spain and Mexico, the main conclusion of this work is that, if in Spain the 
aparecidas en difrentes medios de fear derived from the new coronavirus has been comunicación españoles sobre la pandemia en the one that has frightened the population, in España y México, la conclusión principal de the case of Mexico there is a virus that attacks este trabajo es que, si en España el miedo derivado del nuevo coronavirus ha sido el que ha atemorizado a la población, en el caso de México hay un virus que ataca con mayor virulencia a la población y éste es el virus de la violencia donde solo en 2019 hubo 35.000 homicidios, en 2018 fueron 34.655 y a finales de 2020 ya habían muerto asesinadas 32.759 personas.

Palabras clave: medios de comunicación, COVID-19, fake news, violencia. the population with greater virulence and this is the virus of violence where only in 2019 there were 35,000 homicides, in 2018 there were 34,655 and by the end of 202032,759 people had already died murdered.

\section{INTRODUCCIÓN}

Durante décadas, los medios de comunicación tradicionales han contribuido a la difusión de información y la sociedad ha considerado como cierto aquello que recibía a través de estos. Habitualmente, los medios escritos se consideran fuentes de información veraces, aunque ha sido especialmente la television la que siempre ha tenido una gran credibilidad por la audiencia, de ahí el dicho popular de "ha pasado esto y es verdad porque lo he visto en la televisión". No obstante, como señalan Roses y Gómez-Calderón (2015, p. 437) quienes tienen menos estudios y su consumo informativo se basa en la televisión son quienes menos cuestionan las informaciones, incluso las políticas, que son las que más recelos suscitan entre las audiencias. Pero estas afirmaciones poco a poco van desapareciendo del ideario colectivo, "el modelo del flujo continuo de noticias rechaza algunos valores que eran hasta hace poco considerados pilares del periodismo, como la noción de gatekeeping, la tarea de jerarquizar las noticias y la función de informar a la población sobre los principales temas de interés público" (Salaverría y Desideri, 2015, p. 149).

La gran cantidad de información que se generó en torno al coronavirus ha influido en la opinión pública de manera contraproducente (Vaezi y Javanmard, 2020; Brainard y Hunter, 2020). Desde que se decretara el Estado de Alarma en España, el $63,74 \%$ de las informaciones fueron sobre la COVID-19 (Lázaro y Herrera, 2020), lo que ha podido dar a la población una cierta sensación de estar informada, cuando en realidad la ésta solo está percibiendo una parte de la información sobre una realidad determinada (Ramonet, 1999).

En este sentido, la Organización Mundial de la Salud (OMS) alertó de los peligros de caer en la "infodemia" y las consecuencias que de ello se podían derivar (OMS, 2020; Europa Press, 2020). La información sobre hechos que pueden suponer una amenaza para la población resulta fundamental con el fin de que la población tome conciencia de que debe tomar medidas para protegerse. Es lo que Brainard y Hunter (2020) denominan "comunicación de riesgos", pero esta información debe provenir de fuentes oficiales para no causar precisamente el efecto contrario al deseado.

Si los medios de comunicación pueden ayudar a crear una ciudadanía crítica (Terrones, 2018), más allá de ser meros consumidores de información que no se plantean la veracidad de lo que 
perciben, en este momento más que nunca resulta relevante analizar el mensaje que han transmitido durante los últimos meses, para ver si realmente se ha conseguido o, en la actualidad, sigue vigente el intento de los medios de crear un hombre unidimensional como el que describía Marcuse (1984).

\subsection{Información y desinformación durante la pandemia}

La publicación de informaciones falsas durante la pandemia ha sido una constante, aunque el fenómeno fake news no es nuevo (Parra y Oliveira, 2018; Blanco-Herrero y Arcila-Calderón, 2019). Durante estos meses, la difusión de noticias falsas ha sido muy abundante en las redes sociales (Salaverría et al., 2020) y éstas se han colado en las agendas de los medios de comunicación, normalmente para desmentirlas. No obstante, los medios de comunicación han informado sobre la pandemia dejando patentes sus ideologías. En este sentido, los medios de comunicación más cercanos ideológicamente al partido del Gobierno de España han intentado minimizar el discurso político durante la pandemia, mientras que los medios más cercanos a los partidos de la oposición han querido entrar más de lleno en el debate político de la situación (Román et al., 2020).

Los primeros meses de la pandemia provocada por el coronavirus que produce la enfermedad conocida como COVID-19 han generado un volumen de información quizá como nunca hasta ahora, si se tienen en cuenta las informaciones difundidas a través de los medios de comunicación tradicionales, los medios digitales y las redes sociales. Esa gran cantidad de información que ha circulado, en muchos casos, ha sido información falsa, bien sobre remedios que poco o nada tenían que hacer contra el virus como los que difundió Donald Trump (Román y Sanchez-Gey, 2020) u otros bulos que circularon por diferentes canales de información (Salaverría et al., 2020).

Información y desinformación han convivido durante todo el año 2020, no solo en España sino en todo el mundo. En el caso de México la pandemia ha servido para eclipsar problemas más graves en el país, como es el caso de los asesinatos. En el Estado mexicano, tan solo en el año 2019, hubo 94 muertes diarias por homicidios dolosos. De enero a diciembre de 2019 se registraron 34.000 homicidios y 582 asesinatos, según el dato del propio Secretariado Ejecutivo del Sistema Nacional de Seguridad Pública (Gobierno de México, 2021). Así, mientras que en varios países la alarma y la psicosis del miedo avanzan por la epidemia del coronavirus, en México la muerte por violencia, que es otra gran pandemia, sigue ensañada desde hace años, sin medidas preventivas o investigación para desarrollar una vacuna, entendida como una solución, contra la violencia o medidas correctivas.

Mientras que en varios países tratan de controlar el virus que provoca la COVID-19 con cuarentenas, aislamientos, cancelación de eventos masivos y hasta piden guardar una distancia mínima de un metro entre las personas, en México, la estrategia para terminar con el virus de la violencia, es ofrecer "abrazos" (Sánchez, 2020).

En lugar de enfrentar el problema de la violencia, en México se propician y autorizan eventos masivos donde acuden miles de personas a escuchar, cantar y contagiarse de la violencia por medio de narcocorridos, para aplaudir, vitorear y ensalzar las figuras de personas que son modelo en el crimen organizado. Aunque ello pueda conllevar la muerte (Infobae, 2020). 
El 'virus' de la violencia en México, ha provocado la muerte de más de doscientas mil personas, tan solo en los últimos siete años, los datos son muy esclarecedores de la situación, solo en 2019 hubo 35.000 homicidios, en 2018 fueron 34.655 y a finales de 2020 ya habían muerto asesinadas 32.759 personas, todo ello sin implementar campañas efectivas de control. El origen de ese 'virus' se conoce, está detectado y las 'vacunas' existen, como lo han demostrado en otros países que lo han controlado.

Así, las campañas contra el coronavirus lo único que hacen es desviar la atención de la verdadera epidemia de la violencia que ha costado cientos de miles de vidas, y todavía sin remedios o recursos para controlarla. La caída de la demanda de drogas debida a la pandemia y el confinamiento obligó a los cárteres a diversificar su negocio (Clarin, 2020) por la mayor facilidad de las autoridades estadounidenses para detectar cargamentos sospechosos (Espallargas, 2020), lo cual ha contribuído a aumentar la violencia.

\subsection{El origen de la pandemia}

El origen del contagio de un virus como el que provoca la enfermedad conocida como COVID19, por lo general, parte de un animal, en este caso, hablan del murciélago o el pangolín. La cepa original, es lo que llaman el primer huésped y éste pasa a un huésped intermedio, que genera la cepa humana. El huésped humano pasa una cepa humana de la gripe al mismo animal que se convierte en huésped intermedio. Ambas cepas se mezclan para producir una nueva. La nueva cepa puede pasar de un huésped intermedio a un humano (Corada, 2020, pp. 4-7).

Catedráticos de Sanidad Animal, tanto del Centro de Vigilancia Sanitaria Veterinaria y del departamento de Sanidad Animal de la Universidad Complutense de Madrid (Briones, 2020, p. 27), señalaron que en los mercados húmedos asiáticos pueden encontrarse productos $y$ animales que van de lo exótico a lo excéntrico a los ojos de un occidental. En la cultura china (y en otras) el consumo de animales salvajes es frecuente. Los animales salvajes se mantienen vivos en jaulas inadecuadas esperando ser sacrificados. Este grupo es el más peligroso a efectos de transmisión porque son hospedadores de virus que llegan al consumidor directamente desde la naturaleza sin ningún control sanitario.

Independientemente de la posibilidad de que la cepa original provenga del murciélago, en diferentes épocas, la convivencia del hombre con animales o ingerir carne cruda o de animales salvajes, han representado un riesgo para el desarrollo de epidemias.

Han habido pandemias, como la gripe española en 1918 que fue de las más mortíferas, con un saldo aproximado entre 40 y 50 millones de personas fallecidas al contraer un virus, un ejemplo lo tuvimos en el aviar y el porcino. En 1957, la gripe asiática con epicentro en China mató a dos millones de personas. Fue un virus tipo H2N2. En 1968 fue la gripe de Hong Kong causada por H3N2 y mató a un millón de personas, la mayoría ancianos.

La gripe rusa se presentó en 1977 por el virus HN1N1 que surgió en China, pero entró a Europa a través de Rusia. En 1997 el Virus HSN1 que afectó a personas que habían tenido contacto con aves de corral infectadas con el virus. Murió el 60 por ciento de los contagiados. En 2009 fue la virus H1N1/09, pero esta fue porcina. En 2013 el virus H7N9 que fue un subgrupo entre el grupo más grande de virus $\mathrm{H} 7$ con 33 casos y 11 muertes, y el 31 de diciembre de 2019 en 
Wuhan (Hubel, China) se detectaron casos de neumonía de etiología desconocida, que ahora ya se le identifica como Coronavirus o COVID-19.

Entre las conclusiones de los especialistas está que en la interacción entre la fauna y las personas se encuentra el origen más probable de estas epidemias.

\section{METODOLOGÍA}

El objeto de studio de este trabajo se centra en analizar los mensajes emitidos sobre la situación del coronavirus en España y México, que los medios de comunicación españoles han difundido entre febrero y marzo de 2020, coincidiendo con el primer brote de la pandemia y la declaración del Estado de Alarma por parte del Gobierno español. Para realizer este estudio, el análisis del discurso se presenta como el método más apropiado. Siguiendo a Van Dijk (2005), la teoría del discurso no solo nos ayuda a saber cómo se producen y se entienden los discursos ideológicos sino "las ideologías producidas por los grupos y adquiridas por sus miembros", en este caso las ideologías producidas por los medios y adquiridas por los consumidores de los mismos, atendiendo no solo a los elementos y estructuras discursivas, sino también al contexto en el que se producen.

De este modo, mediante la lectura y el análisis de lo publicado en diversos medios de comunicación acerca del coronavirus se intenta saber hacia qué pensamiento nos han llevado los medios de comunicación durante los meses en los que se produjo el primer brote de la pandemia, haciendo un paralelismo entre España y México.

\section{RESULTADOS. LA PSICOSIS DEL MIEDO}

El miedo es natural en el hombre. Siempre ha existido, pero éste se dispara más cuando se desconoce el origen. El miedo a lo desconocido, por lo tanto, ha sido el factor del coronavirus, sobre todo hasta que se desarrollaron las primeras vacunas que ya se están inoculando a la población. Las imágenes de hoteles y ciudades aisladas, auxiliares o personal de salud con equipo de protección como si fueran astronautas, ciudadanos por las calles con mascarillas o tapabocas, han detonado otro virus: el virus del miedo, que impacta más en la mente de millones de personas que los que han resultado afectados por la pandemia, miles de infectados (Tomás-Sábado, 2020).

La velocidad del miedo, en estos casos, suele ser muchísimo mayor a lo que en realidad representa el problema de salud. El editorial del periódico español El Correo así lo confirma: "una característica común a las crisis sanitarias globales es que el miedo se extiende con una velocidad muy superior a la de las propias epidemias en las que tiene su origen. Con una magnitud que sobrepasa con creces la dimensión alcanzada hasta ahora por el problema" (El Correo, 2020).

"Los cuentos de pánico amenazan a la salud, como se está comprobando con los bulos (rumores) sobre el coronavirus, que trotan desbocados por las redes sociales" (Del Pozo, 2020, p. 56). La rapidez de la dispersión del coronavirus ha estado respaldado en la acción viral de las redes sociales, que siguen tomando datos, rumores, falsas noticias o simples memes, como información sobre la epidemia, sin base científica o respaldo de una fuente seria y acreditada para tratar sobre un problema de salud (Catalán-Matamoros, 2020; Pérez-Dasilva et al., 2020). 
La psicosis se refleja en el uso desmedido de mascarillas pero también de otros muchos productos de higiene que no servían para contener la enfermedad y que se agotaron en los mercados de varios países debido al pánico que se generó entre la población. La tasa estimada de mortalidad de este nuevo coronavirus es el $0.7 \%$, que lo convierte en poco letal si lo comparamos con otros surgidos tiempo atrás como SARS (10\%) o el MERS (21\%). Y el porcentaje de recuperación de las personas que contrajeron la infección del coronavirus es del $97 \%$, a veces con secuelas de las que aún no se concoce el alcance.

El doctor Emilio Boliza, miembro del Instituto de Investigación Sanitaria Gregorio Marañón de Madrid, dice que la alarma y la preocupación están justificados, pero el pánico y el desorden jamás, porque "es triste ver a personas con cuadros de ansiedad comprando mascarillas a precio de oro (o robándolas en los hospitales), como tampoco es edificante el espectáculo del asalto a las estanterías de los supermercados, ni las aglomeraciones en los servicios de urgencias".

Además, según los especialistas, la compra masiva de mascarillas es un sinsentido, pues el acopio que la ciudadanía hizo en un primer momento de las mascarillas y productos desinfectantes, desabasteciendo a las farmacias causó problemas de suministro en clínicas médicas, de un modo que los experos consideraron de irracional. Los especialistas, apuestan por las medidas higiénicas de toda la vida como lavarse las manos con agua y jabón de manera frecuente. "No debemos tocarnos la nariz, los ojos o la boca antes de lavarnos las manos. Lo demás es ridículo" (Osorio, 2020, p. 10).

En el suplemento A tu Salud, se advierte de "reacciones irracionales basadas en la desinformación y el miedo, pues los coronavirus son un grupo muy grande de virus, conocidos desde hace medio siglo, que afectan a los animales y a los hombres, causando infecciones respiratorias, generalmente no graves". La novedad sanitaria ha sido la baja incidencia del problema en niños y adultos jóvenes. Los más afectados han sido personas mayores de 80 años.

Para el director del Instituto de Relaciones Internacionales y Estratégicas de Paris (Bonface, 2020, p. 29), los temores que suscita este virus son solo una amenaza sanitaria, que adopta un giro geopolítico, por sus implicaciones en la economía global. El impacto por los rumores descabellados que se han extendido, con personas cambiando de acera para evitar cruzarse con ciudadanos chinos por miedo al contagio, dando a entender que todos los chinos se han convertido en personas contagiosas. $Y$ destaca la irracionalidad de esas reacciones porque tan solo en 2017 murieron sesenta mil estadounidenses por un virus de la gripe especialmente activo y no ha pasado nada ni se ha hecho tanto ruido mediático.

O el caso de China, donde hay una población de 1,400 millones de personas con una mortalidad promedio mensual de ochenta mil personas. En dos meses, el coronavirus ha causado la muerte de más de dos mil chinos (Bulard, 2020, p. 25).

Otro dato, según el director del Centro de Estudios Postindustriales de Moscú, que no descarta la histeria y pánico actual. Confirma que durante el período actual de gripe que se vive en Estados Unidos y según datos del Centro de Control y Prevención de Enfermedades, dieciséis mil norteamericanos han fallecido por tipos de gripe más severas, dejando a su vez doscientos ochenta mil hospitalizados (Inozemtsev, 2020, p. 27). 
Algunos medios de comunicación han tratado de calmar la psicosis, pero sin muchos resultados. Por ejemplo, el editorial del periódico ABC (2020, p. 4), destaca que las alarmas sanitarias son oportunas pero no el alarmismo, fenómeno que se propaga al margen de cualquier protocolo sanitario y que distorsiona la realidad de una epidemia cuya reducida mortalidad y nivel de contagio no se compadecen con la reacción de la opinión pública. En esta perniciosa espiral de miedo, conviene establecer las responsabilidades de un caos cuyas consecuencias tardaremos tiempo en determinar y asimilar.

No hay duda, que ante este tipo de fenómenos como la coronavirus, los contagios a nivel global y sus efectos en la economía, el papel del impacto mediático y las redes sociales son parte del mismo fenómeno. Estamos viviendo en una sociedad global de la información, pero también de la desinformación.

La doctora Marina Gell, Consejera de Sanidad del 2003 al 2010 en Cataluña, propone elegir el conocimiento como jerarquía ante la masiva información del tema para separar el grano de la paja y desmontar las fake news. Y la propuesta principal es rechazar la infoxicación (información e intoxicación) (Gell, 2020, p. 7).

La Iglesia Católica, a través de su medio Alfa Omega, aporta una interpretación de esta epidemia en el sentido de que no sabemos nada del coronavirus, pero huimos de él, por el miedo a lo desconocido. "Creemos que poseemos las cosas -y lo que es peor, las personasporque eso nos da una sensación de control, nos hace sentirnos seguros porque, como pequeños dioses de nuestras pequeñas cosas, hemos construido un minimundo que podemos medir, del que creemos que podemos saber su principio y su fin. Pero entonces llega el coronavirus y nos recuerda la inevitable levedad de todo" (Vila, 2020, p. 5).

El pánico también se convirtió en discriminación hacia los chinos, como si fueran personas apestadas, que deberían ser relegadas o evitadas. Es muy común, que, en estos casos, la xenofobia pretenda justificar un culpable sobre quien descargar iras o causantes de nuestras desgracias. El miedo a lo desconocido y tener a la vista un probable huésped del virus, conformaron el binomio perfecto para canalizar fobias y pánico.

Para la Directora de Salud Pública de la Organización Mundial de la Salud, María Neira (Corada, 2020, p. 9), hay un desfase en la proporción y en la percepción, como el uso de mascarillas que es totalmente irracional: "No sé de donde salió eso de que todo el mundo se ponga mascarilla, es una especie de falsa protección".

Camilo José Cela Conde (2020, p. 28), afirma que "el pánico se extiende de la mano del temor hacia el apestado, que al principio era, por definición, todo chino pero con rapidez se ha extendido a cualquier otro portador potencial, ya sin rasgos distintivos como son los ojos rasgados, y si el virus corre más que las autoridades sanitarias, el terror generalizado se vuelve instantáneo en el mundo global". En este medio también publicaron testimonios de españoles viviendo en áreas restringidas de Italia, y señalaban que el alarmismo social era el peor virus, precisando que algunos medios de comunicación y las redes sociales estaban haciendo bastante daño.

Ese mismo alarmismo, quedó manifiesto en otro medio con la denuncia de la injustificable alarma social provocada por la sobrevaloración informativa del coronavirus, pidiendo descomprimir la histeria informativa para conducirla a ámbitos racionales. 
"Vivimos tiempos de histerismo, exageración y de susto constante. Los datos son concluyentes, pero la insensatez parece esquivar la realidad constatable. Hay algo peor que el coronavirus: la irresponsabilidad que, trafica con la información sobre él” (Mediavilla, 2020, p. 4).

\subsection{El origen de la pandemia}

Lo que ha aportado esta etapa del coronavirus son varias novedades: la forma en que China recurrió al "big data" y a la inteligencia artificial para contener la epidemia (Rodríguez-Rata, 2020, p. 28), con la utilización de cámaras térmicas, que vigilan la temperatura corporal de los chinos y el desarrollo de aplicaciones para los teléfonos celulares que, imitando al analógico semáforo, clasifican a los ciudadanos hasta condicionarles, qué hacer y con quién relacionarse.

De esta manera identifican a las personas según tres colores: el verde, para quien puede moverse con libertad; el amarillo, para quien había estado o residido en una zona con peligro de infección, razón por la que debía permanecer siete días en cuarentena; el rojo, para quien hubiera estado en contacto con zonas de alta afectación de la COVID-19, estando obligada a permanecer 14 días en cuarentena. Esto hizo volver la mirada a un gobierno controlador, por su capacidad de poner en cuarentena a millones de habitantes.

Otra aplicación que desarrollaron fue para rastrear a las personas y alertar sobre si han tenido "contacto cercano con alguien infectado". Obvio que también fue una razón más para el control del Gobierno sobre los movimientos de los ciudadanos. Es suficiente con escanear un código QR en las plataformas chinas Wechat o Alipay, enviando el nombre, número de teléfono, número de identificación y les advierten si se camina por un lugar con peligro de ser infectado o si se ha viajado cerca de personas infectadas, si se trata de miembros de la familia o de pasajeros y tripulación de un mismo tren o avión. Incluso permite buscar números de identificación diferentes y saber si son un riesgo de salud.

Algunas personas son monitorizadas, sin saberlo. A otros les han impedido salir de sus casas o no ingresar a su residencia e integrantes de los comités vecinales van de puerta en puerta, tomando la temperatura y recogen la información para alimentar dichas aplicaciones.

Gracias también a la big data que han desarrollado, todo mundo se ha encerrado siguiendo las consignas de las autoridades (chinas). En todos los países, a millones de personas les están restringidas, controladas o prohibidas las salidas. Cada día, reciben a través del teléfono móvil estadísticas sobre coronavirus e información del tema como que "más de 16.3 millones de mascarillas falsas han sido incautadas por la policía de Wuhan” (Bulard, 2020, p. 25).

\section{DISCUSIÓN}

Durante siglos y generaciones, la humanidad ha sufrido varias calamidades provocadas por epidemias que han mermado considerablemente la población. Desde las plagas bíblicas que arribaban como castigos divinos hasta nuestros días con la epidemia conocida como "coronavirus" que se detectó en China y que ha impactado de manera global, con gran rapidez y psicosis, por la otra epidemia de información o infodemia (OMS, 2020; Europa Press, 2020); que ha circulado por redes sociales provocando miedos irracionales.

Cada epidemia y pandemia que han mermado a pueblos, han dejado huellas y lecciones con el sello propio de la época. La versión actual del coronavirus ha planteado retos a un gobierno 
rígido -como el chino- que no desdeñó reprimir al mismo médico que detectó el primer brote y quien al final fue víctima de su propio descubrimiento. También aplicó cuarentenas dictatoriales a pueblos enteros, sin permitirles salir de sus casas e implementó medidas preventivas y de diagnóstico recurriendo a la Inteligencia Artificial. Además, el gobierno de Pekín censuró la información negativa sobre el virus que circulaba en los inicios de la pandemia por Internet (ABC, 2020).

Los medios de comunicación han tenido un papel protagonista en esta epidemia, siendo los portadores de información, a veces en cantidad desmesurada, la OMS llegó a hablar de Infodemia, como se dijo con anterioridad. Tal vez, como si fuera un virus del miedo, coronavirus ha despertado una atracción y preocupación, que los mismos científicos califican de exagerada e injustificada.

Surgió en China, pegó en Irán, Corea y Japón. Se trasladó a Europa e impactó principalmente en Italia y luego en varios países. Los medios de comunicación, en esos lugares, la colocaron de manera prioritaria en su agenda, con la abundancia de información, datos, estadísticas y reportes con efectos que la han magnificado, a base de imágenes fuera de contexto, donde publican personas con "tapabocas" dando la impresión de una verdadera pandemia, de un desastre total como si fuera el inicio del Apocalipsis.

Parte de ello se refleja en analistas y comentaristas como Antoni Puigverd (2020, p. 21) quien escribió que la opinión pública ha quedado atrapada en una de las clásicas espirales obsesivas (similar a las de la gripe aviar, las vacas locas o el primer estallido del sida). Que estas espirales responden a otra paradoja contemporánea: en la era de la información es muy difícil estar informado; en la sociedad de la información, las informaciones son tantas que manejan datos sin procesar, en estado crudo, para llegar con naturalidad a la opinión pública.

Su crítica es que son infinitas las noticias, opiniones, explicaciones, mensajes y distracciones que a cada instante circulan por las redes sociales o por los medios tradicionales (prensa, radio, televisión). Esa comunicación actual es tan intensa que produce esencialmente un ruido indescifrable, inagotable, constantemente renovado. Todo el mundo afirma su voz: individuos, empresas, instituciones, publicistas, periodistas, aficionados o profesionales. Todo mundo habla, escribe, fabrica imágenes y envía teorías al infinito océano de las redes sociales.

Más allá del ruido, sostiene este analista de La Vanguardia, el resultado de toda esta insomne actividad expresiva es la trivialización de las noticas, la saturación de las redes, la confusión y la parálisis comunicativa. Lo sabemos todo y no sabemos anda. Pasamos horas pasmados ante las diversas pantallas que nos rodean (teléfono, computadora, televisor) pero cuando nos metemos en la cama, con la cabeza como un bombo, somos incapaces de responder a la pregunta básica: ¿Qué está pasando?

Para los especialistas en comunicación hay dos formas de lograr la atención mediática: vociferar o reiterar. "Si todo el mundo habla sin parar, hay que gritar por encima de la media para hacerse escuchar, de tal manera que, ahora todo el mundo transmite sus mensajes con estridencias insoportables".

La reiteración en el océano mediático es el otro recurso para llamar la atención: los medios convencionales y digitales- "repitiendo o subiendo las notas cada media hora durante el día -o 
noche- son la avanzada obsesiva de estas espirales mediáticas que invaden nuestra vida cotidiana fabricando sin parar vivencias colectivas de todo tipo: políticas, climáticas, económicas y vivencias histéricas, por supuesto. En los últimos años, para expresar el éxito de una noticia, de un tuit, de una canción o de un video se utiliza el adjetivo viral. El triunfo comunicativo es identificado con la propagación masiva y obsesiva de un virus.

Puede afirmarse, por consiguiente, que el coronavirus, aparte de ser un virus, está teniendo un éxito viral en las redes. Se trata de un éxito redundante, que sintetiza la realidad del virus y, al mismo tiempo, metaforiza la comunicación actual. Esta Covi-19 asusta y fascina al mismo tiempo y rige el planeta.

\section{CONCLUSIONES}

La pandemia de COVID-19 ha cambiado nuestras vidas de un momento a otro: crisis sanitaria, crisis económica, millones de personas se han quedado sin empleo, cientos de miles han enfermado y muerto, etc. Pero todos nuestros conocimientos sobre coronavirus los extraemos a diario de los medios de comunicación, porque todo esto sucede fuera de nuestro radio de experiencia, a menos que nosotros mismos o parientes cercanos se vean afectados. Por ello, los medios han adquirido una relevancia enorme, incluso la televisión está experimentando un renacimiento y el consumo de medios ha aumentado drásticamente, porque proporcionan información sobre las cifras actuales y las restricciones que imponen nuestros Gobiernos a sus ciudadanos, entre otras cosas, y nos acercan a lo que sucede fuera de nuestro entorno.

No obstante, los receptores reciben tal cantidad de información que no saben en quién confiar y no siempre son capaces de discernir entre lo que es información y desinformación.

Noticias falsas, fake news o bulos, sobre cómo protegerse contra la COVID-19, se han propagado a través de todos los mass-media, por lo que al periodismo se le presenta una gran responsabilidad: dilucidar y filtrar las informaciones con rigor para transmitirlas correctamente, en ocasiones contradictorias, suministradas por virólogos, economistas y expertos en general.

En este estudio se realiza un paralelismo de la difusión de la pandemia en España y en México y concluimos que México, aparte del virus de la COVID 19, sufre una pandemia de mayor envergadura: el virus de la violencia que ha provocado la muerte de más de 200.000 personas, tan solo en los últimos siete años, en 2019 hubo 35.000 homicidios, en 2018 fueron 34.655 (Beauregard, 2020) y a finales de 2020 ya habían muerto asesinadas 32.759 personas; sin implementar campañas efectivas de control. El origen de ese "virus" se conoce, está detectado y las vacunas existen, como lo han demostrado en otros países que han controlado dicho virus de la violencia.

En México, pese a que han brotado muchos contagios de coronavirus, y han creado una gran campaña de alarma y alerta a los mexicanos, la violencia en México ha matado más, muchas más personas, que lo que pueda hacer el coronavirus en el país y ha desviado la atención de la verdadera epidemia de la violencia que tiene años y que ha costado miles y miles de vidas, y todavía sin remedios o recursos para controlarla.

\section{Referencias}

ABC (28 de febrero de 2020). Coronavirus, de la alarma al alarmismo. $A B C$. 
Angel, A. (29 de diciembre de 2020). En 2020, la violencia en México se mantuvo en niveles récord; en 11 estados aumentaron asesinatos. Animal Político. https://bit.ly/3uYaAdl

Beauregard, L.P. (22 de enero de 2020). 2019 se convierte en el año más violento de la historia reciente de México. El País. https://bit.ly/2T4h4tV

Bonface, P. (2 de marzo de 2020). Cuando China se resfría, estornuda el planeta. La Vanguardia.

Brainard, J. y Hunter, P. (2020). Misinformation making a disease outbreak worse: outcomes compared for influenza, monkeypox, and norovirus. SIMULATION, 96(4), 365-374. https://doi.org/ggmjkj

Briones, V. y Pérez-Sancho, M. (26 de febrero de 2020). Animales, personas, virus. El Correo.

Bulard, M. (marzo de 2020). Una epidemia puede esconder otra epidemia. Le Monde diplomatique en español. https://bit.ly/3qIXcry

Catalán-Matamoros, D. (2020). La comunicación sobre la pandemia del COVID-19 en la era digital: manipulación informativa, fake news y redes sociales. Revista española de comunicación en salud, Suplemento 1. https://doi.org/10.20318/recs.2020.5531

Cela Conde, C. (29 de febrero de 2020). Pandemia. La Opinión - El Correo de Zamora.

Clarín (22 de mayo de 2020). Coronavirus en México: la pandemia obliga al narcotráfico a cambiar de estrategia. Clarín. https://bit.ly/38ATABw

Corada, E. (1 de marzo de 2020). Coronavirus. Las incógnitas que quedan por despejar sobre Covi-19. Suplemento A tu Salud, La Razón.

Corada, E. (1 de marzo de 2020). Nuestro objetivo no es controlar el virus, sino combatirlo. La Razón.

Del Pozo, R. (2 de marzo de 2020). Bulos que trotan por las redes. El Mundo.

Díez, P.M. (15 de febrero de 2020). El régimen chino pone en cuarentena a los activistas del coronavirus. $A B C$. https://bit.ly/2NelsTo

El Correo (26 de febrero de 2020). Precaución sin alarmismos. El Correo. https://bit.ly/38CUYDA

Espallargas, A. (23 de mayo de 2020). La pandemia pone a los narcos mexicanos también en cuarentena. $A B C$. https://bit.ly/3cyrHeu

Europa Press (2 de febrero de 2020). La OMS lanza una campaña contra la desinformación sobre el nuevo coronavirus. Europa Press. https://bit.ly/3bKM21e

Gell, M. (3 de marzo de 2020). Coronavirus: gestionar la incertidumbre. El periódico.

Secretariado Ejecutivo del Sistema Nacional de Seguridad Pública (25 de mayo de 2021). Incidencia delictiva. Gobierno de México. https://bit.ly/3cpi6Ym

Infobae (24 de diciembre de 2020). Cantar narcocorridos, una sentencia de muerte en el violento mundo del crimen en México. Infobae. https://bit.ly/3tiLHzk

Inozemtsev, V. (3 de marzo de 2020). ¿Un segundo Chernóbil? La Razón.

Mediavilla, K. (29 de febrero de 2020). Que dejen de convocar al pánico, Deia.

OMS (23 de septiembre de 2020). Gestión de la infodemia sobre la COVID-19: Promover comportamientos saludables y mitigar los daños derivados de la información incorrecta y falsa. Organización Mundial de la Salud. https://bit.ly/3voBfl6

Osorio, S. (1 de marzo de 2020). El reto es que el avance del virus sea lento. El Correo.

Pérez-Dasilva, J.-A.; Meso-Ayerdi, K. y Mendiguren-Galdospín, T. (2020). Fake news y coronavirus: detección de los principales actores y tendencias a través del análisis de las conversaciones en Twitter. Profesional De La Información, 29(3). https://doi.org/10.3145/epi.2020.may.08

Puigverd, A. (2 de marzo de 2020). La corona del virus. La Vanguardia.

Ramonet, I. (1999). Prólogo en Ramonet, I.; Bustamante, E.; Correa, M.; Aliaga, J.; Hens, M.; Zeller, C.; Armada, A.; Sánchez, G.; Sáez Munilla, J. ; Sánchez Parga, J.; Aguirre, M.; Buisef, D.; Cascón, P. y Aznar, C. Sur y comunicación: una nueva cultura de la información. Icaria. 
Rodriguez-Rata, A. (2 de marzo de 2020). El coronavirus legitima en China las tecnologías de control de los ciudadanos, La Vanguardia.

Román San Miguel, A. y Sánchez-Gey Valenzuela, N. (2020). Tratamiento informativo de las fake news y su relación con los remedios falsos difundidos por Donald Trump durante el estado de Alarma por el COVID-19 en Hidalgo Marí, T.; Herrero Gutiérrez, J. y Segarra Saavedra, J. (coord.). Comunicación, periodismo y publicidad. Retos profesionales en tiempos de crisis (pp. 205-217). Fragua.

Román San Miguel, A.; Sánchez-Gey Valenzuela, N. y Elías Zambrano, R. (2020). Las fake news durante el Estado de Alarma por COVID-19. Análisis desde el punto de vista político en la prensa española. Revista Latina de Comunicación Social, (78). https://doi.org/fpvp

Roses, S. y Gómez-Calderón, B. (2015). Credibilidad de los medios en España: divergencias de percepción y caracterización de los escépticos. El profesional de la información, 24(4), 432-439. https://doi.org/f2d8

Salaverría, R.; Buslón, N.; López-Pan, F.; León, B.; López-Goñi, I. y Erviti, M.-C. (2020). Desinformación en tiempos de pandemia: tipología de los bulos sobre la Covid-19. El profesional de la información, 29(3). https://doi.org/d96z

Salaverría, R. y Desideri, L. (2015). El flujo continuo de noticias y sus efectos en VV.AA. El nuevo diálogo social: organizaciones, públicos y ciudadanos (pp. 149-160). Campgràfic. http://doi.org/10.13140/RG.2.1.4326.9201

Sánchez Olmos, P. (2 de julio de 2020). "Abrazos y no balazos": la estrategia fallida de López Obrador contra la violencia en México. El Mundo. https://bit.ly/3/gR7S8

Terrones Rodríguez, A.L. (2018). Pensamiento dominante, educación y medios de comunicación. Sophia, (24), 313-336. https://doi.org/f2d9

Tomás-Sábado, J. (2020). Miedo y ansiedad ante la muerte en el contexto de la pandemia de la COVID19. Revista de enfermería y salud mental, (16), 26-30. https://doi.org/f2fb

Vaezi, A. y Javanmard, S.H. (2020). Infodemic and Risk Communication in the Era of CoV-19. Advanced biomedical research. 9(10). https://doi.org/ggv4zg

Van Dijk, T.A. (2005). Ideología y análisis del discurso. Utopía y Praxis Latinoamericana, 10(29), 9-36. https://www.redalyc.org/pdf/279/27910292.pdf

Vila, G. (27 de febrero al 4 de marzo de 2020). Coronamiedo. Alfa Omega.

\section{Semblanza de los autores}

\section{Pastora Moreno-Espinosa}

Catedrática del Departamento de Periodismo II de la Universidad de Sevilla, con ejercicio docente en la Facultad de Ciencias de la Información.

Ha sido profesora visitante en diversas Universidades: Bruselas, Bolonia, Milán Verona, Universidad Nacional de Chengchi en Taipei (República China de Taiwan), Universidad de Mérida-Yucatán (México), Universidad de las Américas (Puebla), Universidad Autónoma de Chihuahua, Universidad de San Salvador, Radiotelevisión de Veracruz, Universidad Veracruzana, Universidad Anahuac de Cancún, Universidad de La Habana, etc.

Es Directora del Equipo de Investigación en Géneros Audiovisuales e Imágenes, EGAUDIM. Ha colaborado en diferentes medios de comunicación, tanto de Prensa como de Radio y Televisión y ha participado en numerosos Seminarios, Simposios y Congresos nacionales e internacionales con ponencias y comunicaciones.

\section{Javier H. Contreras Orozco}

Doctor en Ciencias de la Información; estudió filosofía y cuenta con una maestría de Ciencias políticas y sociales. Académico y consultor en carreras de periodismo y Ciencias de la 
Información en la Universidad Autónoma de Chihuahua. Ejerce el periodismo desde 1977 y es director general de El Heraldo de Chihuahua.

\section{Aránzazu Román-San-Miguel}

Doctora en Periodismo por la Universidad de Sevilla, es Profesora Ayudante Doctora en el departamento de Periodismo II y ayudante de dirección y profesora del Máster en Periodismo Deportivo en la universidad hispalense. También ha sido co-coordinadora y profesora del Máster en Comunicación Institucional y Política, actualmente pertenece a la Comisión de Calidad de este máster oficial de la Universidad de Sevilla. Ha escrito varios libros, capítulos de libro y artículos en revistas sobre periodismo audiovisual. Ha realizado estancias de investigación en la Universidad Complutense de Madrid, en la Universidad de Castilla La Mancha y en la Universidad Pontificia Salesiana de Roma. 